\title{
Flake morphology as a record of manual pressure during stone tool production
}

Alastair Key $^{1 *}$, Christopher J. Dunmore ${ }^{1}$, Kevin G. Hatala ${ }^{2,3}$, and Erin Marie WilliamsHatala $^{2,3}$

* Corresponding author: a.j.m.key@ kent.ac.uk ～+44(0)1227827056

${ }^{1}$ Skeletal Biology Research Centre, School of Anthropology and Conservation, University of Kent, Canterbury, Kent, CT2 7NR, UK

${ }^{2}$ Department of Biology, Chatham University, Pittsburgh, PA 15232, USA

${ }^{3}$ Center for the Advanced Study of Human Paleobiology, George Washington University, Washington, DC 20052, USA 


\begin{abstract}
Relative to the hominin fossil record there is an abundance of lithic artefacts within Pleistocene sequences. Therefore, stone tools offer an important source of information regarding hominin behaviour and evolution. Here we report on the potential of Oldowan and Acheulean flake artefacts to provide a record of the biomechanical demands placed on the hominin hand during Lower Palaeolithic stone tool production sequences. Specifically, we examine whether the morphometric attributes of stone flakes, removed via hard hammer percussion, preserve correlates of the pressures experienced across the dominant hand of knappers. Results show that although significant and positive relationships exist between flake metrics and manual pressure, these relationships vary significantly between subjects. Indeed, we identify two biomechanically distinct strategies employed by knappers; those that alter their hammerstone grip pressure in relation to flake size and mass and those who consistently exert relatively high manual pressures. All individuals experience relatively high gripping pressure when detaching particularly large flakes. Amongst other results, our data indicate that the distinctive large flake technology associated with the Acheulean techno-complex may be demonstrative of an ability to withstand, and by extension, to exert higher manual pressures. However inferences from smaller flake artefacts, especially, must be treated with caution due to the variable biomechanical strategies employed.
\end{abstract}

Keywords: Knapping, Force, Skill, Lower Palaeolithic, Hand, Hammerstone 


\section{Introduction}

The production of stone tools represents one of the few known behavioural constants amongst hominin populations during the last $\sim 3$ million years. Lithic artefacts also represent one of the most abundant sources of evidence available relating to the evolution of humans. Archaeologists and palaeoanthropologists have, therefore, long been concerned with how Palaeolithic artefacts may be used to shed light on our evolutionary history. Given the high cognitive demands associated with stone tool production techniques, a great deal of this attention has been focused on how the lithic archaeological record may inform our understanding of the evolution of human cognitive capabilities (Beaune et al., 2009; Gamble et al., 2014). These capabilities include the evolution of language, imitation, complex technological capabilities, increased brain size, complex social systems, cognitive and manual lateralisation, spatial cognition and shape recognition (Ambrose, 2010; de Beaune, 2004; Gowlett et al., 2012; Morgan et al., 2015; Schillinger et al., 2015; Stout, 2011; Stout et al., 2008; Uomini and Meyer, 2013; Wynn, 2002). Comparatively little work has investigated how lithic artefacts may be used to further our understanding of the evolution of human musculoskeletal anatomy and biomechanical capabilities.

Previous research examining relationships between lithic technology and the hominin upper limb has principally been concerned with identifying how stone tool use and production may plausibly have exerted selective pressures on anatomical features. This has included investigations into muscle recruitment levels, upper limb kinematics, manual pressure and force distributions, grip requirements and how tool-user biomechanical variation influences the efficiency of tool use or production (Hamrick et al., 1997; Key and Dunmore, 2015; Key and Lycett, 2011, in press; Maki, 2013; Marzke and Shackley, 1986; Marzke et al., 1998; Rolian et al., 2011; Shaw et al., 2012; Williams et al., 2010, 2012, 2014). Little of this work, however, addresses how Palaeolithic artefacts may be of use beyond their presence in the archaeological record confirming that stone tool related behaviours were being undertaken.

At a broad level, Marzke and Shackley (1986) demonstrated that flake, handaxe, and blade manufacturing techniques are all manually demanding, but require diverse and at times distinct manipulative actions. Faisal et al. (2010) compared the manual complexity of Oldowan and Acheulean stone tool production sequences in more detail and identified similar levels of grip complexity and diversity in each. In turn, it could be argued that the onset of the Acheulean 900 Kya after the development of Oldowan technology may not have necessarily been 
consequent to changes in the manipulative anatomy of Lower Palaeolithic hominins. More recently, Key, Stemp and colleagues have investigated how lithic microwear traces may potentially be used to investigate the loading levels which hominins applied during stone tool use (Key et al., 2015; Stemp et al., 2015). Their research indicates that microwear traces may be used, potentially, to examine how stone tool use proficiency developed in relation to the evolution of the hominin upper limb. Others have since suggested that lithic microwear traces may be similarly used to reconstruct manual gestures and handling techniques associated with the use of Palaeolithic scraping technologies (Pfleging et al., 2015; Zupancich et al., 2015). Relatedly, Bello and colleagues demonstrated how the micromorphological analysis of cutmarked bones may be used to infer the working forces and manual application of stone tools (Bello, 2011; Bello et al., 2009). These important studies go beyond simply treating Palaeolithic artefacts as a binary indicator of their production or use, but instead emphasize the manual complexity required to produce such technology or how the traces of tool use could be used to infer biomechanical capabilities of Palaeolithic individuals.

The biomechanical capabilities of Palaeolithic hominins have on occasion been considered during investigations of lithic artefacts, however, these have largely been limited to comments made within research with an alternative focus. Gowlett (2015), for instance, has recently noted during a comparison of Acheulean and chimpanzee artefacts that a reoccurring average weight of $\sim 0.5 \mathrm{Kg}$ within biface assemblages probably has a biomechanical origin. Delagnes and Roche (2005) were more specific during their analysis of the 2.34-million-yearold assemblage from Lokalalei $2 \mathrm{C}$ in West Turkana when noting that the precise and highly controlled flaking that they observed "implies not only a highly controlled movement [by the tool producers], but also a firm and constant grasp while handling both core and hammerstone". In their description of the 3.3 Mya stone tools from Lomekwi, West Turkana, Harmand et al. (2015) similarly discussed their implications for the evolution of modern human-like manipulative capabilities. While providing a holistic review of all manipulative observations derived from Palaeolithic research is beyond the remit of this paper, to our knowledge, there are few studies that investigate how different technological or morphological aspects of the Palaeolithic record may preserve information relating to the upper limb biomechanics of PlioPleistocene hominins.

One potentially fruitful line of enquiry in this regard was raised by Dibble and Rezek (2009) during their investigation into how a number of variables relevant to knapping, including the striking force of the hammerstone, may influence the size and shape of removed 
flakes. Dibble and Rezek (2009: 1953) identified a "clear association between force and flake weight, suggest[ing] that it may ultimately be possible to determine the actual force used to detach flakes recovered archaeologically". A similar relationship between the kinetic energy of hammerstones during flake removals and flake size has been noted by Nonaka et al (2010). Certainly, within mechanical literature flake size is known to be in part a function of the forces applied during fracture propagation (Chai and Lawn, 2007; Cotterell and Kamminga, 1990). Hammerstone reaction forces and the need to maintain a secure grip on said stone during striking actions can, then, result in high pressures acting on the hand (Rolian et al., 2011; Williams et al., 2012). It is thus logical to predict that there may be direct relationships between the size or mass of flake stone tools and the manual pressures experienced by stone tool producers in their dominant (hammerstone holding) hand. Therefore, flake artefacts may potentially contain information relevant to our understanding of the loads that were routinely placed on the hands of Palaeolithic hominins and which may have influenced the evolution of the human hand.

Here, we experimentally test whether there is a relationship between the morphology or mass of flakes produced during stone tool production sequences and the pressures experienced by the hammerstone-holding (dominant) hand during their detachment. Specifically, we attach pressure sensors to the distal phalanges of the thumb, index and middle fingers of nine experienced knappers during Oldowan flake production and Acheulean handaxe shaping. Through the comparison of the manual pressures experienced during a flake's removal and its resultant morphometric attributes, we address whether flake stone artefacts may contain information relating to the manual pressures experienced by Palaeolithic hominins during stone tool production sequences. However, research has repeatedly highlighted that complex relationships exist among a range of independent factors that can influence the final form of stone flakes (Chai and Lawn, 2007; Cotterell and Kamminga, 1987; Dibble and Whittaker, 1981; Magnani et al., 2014) and as such, direct relationships between flake size or mass and hammerstone striking force should be "viewed with considerable caution" (Magnani et al., 2014: 47). Hence, we also analyse inter-individual variation to examine the relative relationships between flake morphometrics and manual pressure in an attempt to naturalistically control for such factors as varying levels of skill, differing core preparation strategies, and individual learned behaviours. Results are discussed in terms of whether Lower Palaeolithic flake forms are able to shed light on the evolution of the human hand and our ability to manipulate hammerstones forcefully and dexterously. 


\section{Materials and Methods}

\section{Participants and Experimental Protocol}

Nine individuals experienced in stone tool replication were recruited to take part in the experiment. Each had at least 3 years of experience producing stone tools and had the ability to consistently produce Acheulean handaxes when intended. Notably, some of the participants exceed this technological capability by a considerable margin and are known to demonstrate expertise within a variety of stone tool replication conditions (e.g. Eren et al., 2013; Winton, 2005). Descriptive data for individual participants are presented in Table 1. This includes basic biometric data from the dominant hand of each individual and potential indicators of knapping skill. Hand length was measured along the palmar surface from the distal tip of the $3^{\text {rd }}$ digit to the first crease line at the wrist. Grip and pad-to-side pinch strength were measured using a Jamar dynamometer and pinch-strength gauge, respectively. Flaking success was calculated by dividing the number of flakes removed by each participant by the total number of hammerstone strikes when attempting to produce these flakes, expressed as a percentage. Flaking success was calculated separately for the two flake removal sequences performed by each participant.

Each participant was asked to undertake both an Oldowan and Acheulean flake production sequence. In line with general consensus regarding the primary objectives of Oldowan stone tool production sequences (e.g. Stout et al., 2010; Toth, 1985), participants were asked to produce stone flakes that may conceivably be used as cutting tools. The Acheulean flake production sequence was similarly undertaken with respect to general consensus regarding the objectives of 'typical' Acheulean stone tool production sequences. Individuals were asked to produce a handaxe (that characterises the Acheulean techno-complex [Lycett and Gowlett, 2008]) through the bifacial removal of flakes around the circumference of a larger stone core/flake spall (here, all handaxes were produced from cores). In each condition individuals were provided with a large nodule of British flint and were asked to remove a minimum of 30 flakes. Nodules varied in size, but all displayed minimum dimensions that were at least $18 \mathrm{~cm}$ in length, $15 \mathrm{~cm}$ in width, and $8 \mathrm{~cm}$ in depth. All individuals undertook the Oldowan flake production sequence prior to the Acheulean handaxe sequence.

In an attempt to control for the possible influence that the size and mass of a hammerstone may have upon relationships between flake form or mass and manual pressure requirements, all participants were provided with the same set of hammerstones of a known size and mass 
(Figure 1; Table 2). There were no restrictions with regards to if or when an individual could use one of the hammerstones during the reduction sequences. For every flake removed a record of which hammerstone used was made.

\section{Manual Pressure Records}

The pressures experienced by the dominant hand during hammerstone strikes were recorded using a wireless Novel Pliance ${ }^{\circledR}$ system. This system records pressure (ranging from 15-600 $\mathrm{kPa}$ ) using a textile-based sensing system with capacitive sensors ideal for flexible anatomical regions, like that of hand. Here, we attached $17 \times 17 \mathrm{~mm}^{2}$ (sensing area $289 \mathrm{~mm}^{2}$ ) pressure sensors to the palmar surfaces of the distal phalanges of digits 1-3 (Figure 2). This allowed pressure to be recorded from the most heavily recruited aspects of these digits during hammerstone use (Williams et al., 2012). Digits 4 and 5 were not examined here as they are infrequently recruited during hammerstone use (Williams-Hatala et al., 2016). Individual sensors were secured to the palmar surface of each digit using double-sided tape and a Velcro strap attached to the margins of the sensor was wrapped around the dorsal aspect of the digit (Figure 2). A latex finger cot was rolled over the entire digit further securing all of the sensors on a given digit (Figure 2). Sensors were unloaded and "zeroed" out before data capture to remove any potential effects of the attachment apparatus.

All pressure data were recorded at $200 \mathrm{~Hz}$. Data were collected from individuals during brief periods that directly related to each hammerstone strike. Data that occurred between 1.5 seconds before a strike and 1.7 seconds after strike (i.e. 3.2 second segments) were extracted and maximal pressure $(\mathrm{kPa})$ values were identified in each instance. In between flake removals participants were allowed to assess the form of the core they were reducing, identify the flake that they wished to remove next, change their grip or hammerstone choice, prepare striking platforms, and readjust the core in any way that they saw fit. Once participants indicated that they were ready, another flake removal was attempted.

\section{Recording the Form and Mass of Flakes}

Nine variables were recorded from each of the flakes produced. All of these variables have been frequently discussed with regards to their influence upon the forces required to detached flakes from stone cores (e.g. Cotterell and Kamminga, 1987; Dibble and Rezek, 2009; 
Dogandžić et al., 2015; Magnani et al., 2014). The first was a record of flake 'Mass' (recorded in grams using digital scales). An additional four traits described the gross size of the flake. These included a record of 'Maximum Dimension', defined as the greatest length able to be recorded in a straight line between any two aspects of a flake's edge, 'Length', defined as the greatest measurement able to be recorded along the ventral surface of a flake perpendicular to its platform, 'Width', defined as the greatest measurement along the ventral surface of the flake perpendicular to Length, and 'Thickness', defined as the greatest measurement possible on a flake that is perpendicular to both Length and Width (i.e. between the opposing ventral and dorsal surfaces of a flake; Figure 3). In addition to this, 'Platform Depth' was recorded from all flakes as the greatest distance measureable on a flake's platform perpendicular to its ventral and dorsal surfaces. These five morphological attributes were recorded in $\mathrm{mm}$ using digital calipers.

The 'Exterior Platform Angle' (EPA; also known as the 'Initiation Angle' [Cotterell and Kamminga, 1987]) of each flake was recorded using a digital photo taken so that both the platform and dorsal surface of each flake were in line with the cameras perspective. This was then uploaded into the image analysis software ImageJ (Abramoff et al., 2004) and the 'Angle Tool' was used to record the angle produced between the flake's platform and dorsal surface (Figure 3). Two further variables that describe the shape of a flake were also recorded. Flake 'Elongation' and 'Relative Thinness' represent composite attributes created by dividing a flake's Length by its Width, and Width by its Thickness, respectively. Elongation describes how long and thin a flake is while Relative Thinness describes how narrow a flake is between its two opposing surfaces relative to its plan view width. For flakes displaying crushed platforms, Platform Depth and EPA could not be recorded and thus these flakes were not included in analyses of these variables.

\section{Data Analysis}

The Pliance ${ }^{\circledR}$ (novel GmbH, Munich, Germany) system records pressure acting on the sensors over a given period of time at a given frequency. From that period, the maximum pressure $(\mathrm{kPa})$ recorded by each sensor during a flake detachment were extracted for the present analyses. Maximum pressure records for each distal phalanx usually occurred during the point of impact between the hammerstone and flint core (although there was notable variation dependent upon the individual knapper). 
Our first set of analyses investigated relationships between flake attributes and manual pressure at a broad 'group' level for both Oldowan and Acheulean reduction sequences (i.e. data from all nine participants were combined). This was achieved using linear regression, with the pressure data within each type of reduction being regressed individually against the Mass, Platform Depth, EPA, Elongation, and Relative Thinness of their respective flakes. These analyses were undertaken separately for each digit to see if there were statistically significant relationships between the manual pressures experienced by the knappers and the attributes of flakes produced $(\alpha=0.05)$. Flake 'Size' was investigated at a gross level and used all four size measurements recorded from the flakes (Maximum Dimension, Length, Width and Thickness). Hence, in order to investigate the relationship between manual pressure and flake size, multiple regression analysis was used whereby these four size measurements were regressed against manual pressure records. In a similar respect to the preceding analyses, multiple regressions were undertaken individually for each digit and type of flake production sequence. To control for Type 1 Error a conservative Bonferroni correction was applied such that $\alpha=0.008$.

Our second set of analyses combined experimental Oldowan and Acheulean production sequences to assess relationships between flake form or mass and manual pressures on an individual participant basis. We chose to focus upon two of the most widely discussed form attributes of flake artefacts; flake Mass and Size (although also see Supplementary Material 1). Flake 'Size' was again investigated at a broad level, such that all four flake dimensions (Maximum Dimension, Length, Width and Thickness) were regressed against pressure values using multiple regression analysis. Flake Mass was linearly regressed on manual pressure. To control for Type 1 Error a Bonferroni correction was applied such that $\alpha=0.002$. Analysis of covariance (ANCOVA) was subsequently used to examine differences in the observed relationships across knappers such that individual differences in the strength of their flake form/manual pressure relationships could be compared on a relative basis.

\section{Results}

In total, pressure was recorded from 383 Oldowan and 403 Acheulean attempted flake removals, of which 276 and 291 (respectively) were successful (i.e. removed a flake). Only data from successful flake detachments was utilised. Descriptive data for the nine variables recorded from each flake are available in Tables 3 and 4. The second participant did not use the distal aspect of his third digit when gripping the hammerstone and consequently no pressure 
records exist for the respective sensor in this instance. Hence, this individual was removed from all analyses including the $3^{\text {rd }}$ digit (i.e. there are eight participants included in the relevant analyses).

Regressions of Mass against manual pressure for the three digits returned relatively consistent results across both reduction strategies. Indeed, results indicate that there is a significant and positive relationship between flake Mass and the pressure experienced in the thumb and index finger of knappers during Oldowan flake production and in the index finger during Acheulean handaxe shaping (Table 5; Supplementary Material 2). In other words, the knappers experienced greater pressure on these distal phalanges when producing heavier flakes, though the relationships were modest $\left(\mathrm{R}^{2}=.032-.166\right)$. In all instances the pressure experienced by the third digit did not significantly alter in response to variation in flake mass. The multiple regressions examining the relationships between flake size and manual pressure during Acheulean handaxe production returned significant results for all distal phalanges examined (Table 5; Supplementary Material 2). In the same analyses of Oldowan flake production, the pressure-size relationship was significant only for the index finger.

The relationships between pressure and the depth and exterior angle of a flake's platform are less consistent than those between pressure and either mass or size (Table 5). Indeed, each flake attribute only displays a significant relationship with pressure in one type of reduction. Exterior Platform Angle varied significantly with pressures on the distal phalanges of the thumb and index during the Acheulean reduction sequence, while Platform Depth showed a significant relationship with pressures of the index finger during the Oldowan condition. Elongation and Relative Thinness (i.e. the "shape" variables) did not have a significant relationship with digit pressures for either reduction type (Table 5). Hence, it appears that the pressures recorded at the point of contact between the hammerstone and the distal phalanges of stone tool producers do not vary as a response to the shape of flake being produced.

Regressions undertaken on an individual knapper basis reveal a general distinction between two groups of participants. Participants 1 and 9, and perhaps less so participants 2, 3 and 7, show significant relationships between manual pressure and flake mass and flake size (this pattern is clearer prior to the conservative Bonferroni correction applied). These relationships account for between 15-40\% of the pressure variation observed (Table 6; Supplementary Material 2). Conversely, participants 4-6 and 8 returned no significant relationships with either mass or flake size. Hence, there appear to be distinctions between knappers with regards to the 
biomechanical strategies employed during the production of variably sized stone flakes (Figure 4).

ANCOVA analyses examined the significance of any differences between the relationships observed between manual pressure and flake attributes for the two groups of knappers (i.e. participants 1-3, 7, and 9 whose regressions were significant were grouped together and compared against participant 4-5 and 8 who did not return significant regressions). Analyses were performed with regards to flake Mass and Length. Results indicate that for both flake attributes and across all three digits, there were significant differences in the nature of relationships observed between the two groups of knappers (Table 7; Figure 5)

\section{Discussion}

Co-dependent and co-evolutionary relationships between aspects of the Palaeolithic record and the hominin hand have long been discussed within archaeological and anthropological literature (e.g. Krantz, 1960; Napier, 1962; Washburn, 1959). In recent years, discussion in this regard has increasingly come to the fore within both fields (e.g. Almécija and Alba, 2014; Almécija et al., 2015; Harmand et al., 2015; Key, 2016; Key and Lycett, in press; Kivell, 2015; Lycett and von Cramon-Taubadel, 2015; Maki, 2013; Marzke, 2013; Pfleging et al., 2015; Skinner et al. 2015; Stemp et al., 2015; Stephens et al., 2016; Tocheri et al. 2008; Williams et al. 2012). The present experiment set out to investigate whether the morphological attributes of knapped stone flakes may contain information relating to the manual pressures experienced during Oldowan and Acheulean stone tool production sequences. If so, it would be possible to assess whether the form of basic flakes (tools and debitage), which are the most ubiquitous of Palaeolithic artefacts, may preserve information relating to the manual loads experienced by Lower Palaeolithic hominins, and in turn, the evolution of the human hand.

Our results demonstrate that, overall, there is not a straightforward relationship between flake mass or flake size and manual pressures during stone tool production. When all knappers were combined, the removal of relatively larger flakes (both in mass and in size) resulted in greater pressures being experienced by some distal phalanges (particularly the thumb and index finger) of the hammerstone-holding hand during both Oldowan and Acheulean reduction strategies. Thus it may be tempting to conclude that the presence of relatively larger flakes within Lower Palaeolithic assemblages suggests that increased pressures were being experienced and resisted by the hands of stone tool producing hominins. When the relationship between flake attributes 
and manual pressure was investigated on an individual knapper level, however, there were clear and significant distinctions between participants. That is, while five of these skilled knappers returned significant and positive relationships between flake size or mass with manual pressure, four individuals did not (Table 6, Figure 4). While this diverging pattern contributed to the weak relationships observed in the first set of analyses, it adds complexity to inferences that may be applied to the artefact record. Certainly, the morphological attributes of flake artefacts alone do not appear to be a reliable indicator of the manual pressures experienced during the detachment of stone flakes. It is, however, notable that all knappers examined here experienced relatively high manual pressures when detaching particularly large flakes (Figure 5). Indeed, while relationships between flake size and pressure are variable amongst knappers during the production of smaller flakes, the increased pressures acting on the phalanges during the removal of larger flakes suggests that knappers may have grasped the hammerstones with greater force during these flake detachments.

Although the recently described 3.3 Mya flake tools from Lomekwi 3 are relatively large (mean length $=120 \mathrm{~mm}$ ) they are described as being produced via anvil-hammer or bipolar techniques (Harmand et al. 2015). It is, therefore, even more difficult to draw straightforward biomechanical inferences relating to these artefacts from the present experiment as they employ differing percussive techniques. The onset of the Acheulean techno-complex at $\sim 1.75$ Mya is, however, often linked with the capability by hominins to detach large $(>10 \mathrm{~cm})$ flakes with hammerstones (Isaac, 1969; Semaw et al., 2009; Sharon, 2009). Our results do, then, suggest that relatively great manual pressures were able to be exerted and resisted by Acheulean hominins during precision gripping behaviours (cf. Marzke, 1997). Although this does not necessarily mean that earlier (Oldowan) hominin populations were not capable of particularly forceful precision grips. When combined with recent experimental data indicating that handaxes would have been an inefficient tool to use prior to hominins displaying relatively large manual dimensions (Key and Lycett, in press), there appears to be increasing evidence linking key aspects of the Acheulean techno-complex with specific biometric conditions or biomechanical capabilities.

It may be reasonably expected that the two groups of knappers could be distinguished on the basis of the potential indicators of skill presented in Table 1 but this is not the case. Certainly, all individuals included in this study are skilled in replicating Lower Palaeolithic stone technologies. Unlike previous studies examining variable stone tool forms (e.g. Roux and David, 2005; Roux et al., 1995; Stout, 2002; Weedman Arthur, 2010; Winton, 2005), the 
biomechanical patterns identified here do not, therefore, appear to be dependent upon differences in 'skill' or 'expertise' (although such qualities are difficult to define). Instead, we suggest the variable relationships between pressure and flake form observed here may be the results of differing choices (conscious or subconscious) in knapping technique. That is, some individuals pursue a strategy that actively alters pressure records between the hammerstone and hand in response to flake mass or size variation, while others do not.

Mechanically, larger flakes require the production of longer fractures during their detachment, which are, in turn, a function of the increased velocity or weight of an indenture (in this case the hammerstone; Cotterell and Kamminga, 1990; Dibble and Rezek, 2009 [although also see Magnani et al., 2014]). It is, therefore, not possible for individuals to remove variably sized flakes with consistently relatively low hammerstone striking forces. Thus, we propose that those individuals that do not alter their grip pressure in response to flake size or mass are, at times, experiencing greater reaction pressures at the point of contact with a hammerstone than those that do alter their grip force. Further, this may indicate that their applied strike force is greater than strictly necessary during the removal of smaller flakes and that they are consequently experiencing greater reaction loads than necessary given the dimensions of the resulting flake. Figure 5 adds credence to this interpretation as those knappers that do not alter their strategy such that manual pressure changes in relation flake length and mass, experience relatively greater pressure during the removal of smaller flakes. Thus, this study reveals two biomechanically distinct strategies relating to the detachment of flakes of variable size or mass. Within the first, individuals alter their manual biomechanical strategy with respect to the size and/or mass of the flake being struck from a core. The second, however, is defined by what appear to be excessive loads acting on the hand during the detachment of relatively smaller flakes. Given that larger flakes are more typically detached towards the start of a reduction sequence (Newcomer, 1971), it may be predicted that skilled knappers similarly experience loads that are commensurate with critical load to failure when producing the first (and largest) flakes in a sequence. However, as more flakes are removed and their size decreases, some individuals alter their biomechanical strategy in response, while others do not and consequently experience excessive reaction pressures.

It could be argued that variation in pressure during the striking of smaller flakes might be the result of different hammerstone choices. A post-hoc Mann-Whitney U test, however, revealed that during the detachment of the smallest (as determined by mass) $50 \%$ of flakes by each individual, those with significant and non-significant relationships used, on average, similarly 
sized hammerstones $(P=.895)$. The distinctions in manual pressure observed when removing small flakes is, therefore, unlikely to reflect hammerstone choices. Further, there are no clear relationships between flake attributes and either the size or strength of participant hands (Table 1; Figure 6), and thus, relationships between pressure and flake attributes do not appear to be explained via biometric parameters of individual knappers. Studies examining the formation of variable flake forms stress the potentially crucial role of a flake's platform depth (also described as 'Platform Thickness' elsewhere) and exterior platform angle in the determination of a flake's size (Dibble and Rezek, 2009; Dibble and Whittaker, 1981; Magnani et al., 2014). Even here, however, there do not appear to be any clear distinctions between the two groupings of knappers with regards to the mean or standard deviation values of these two attributes (Table 4). Differences between knappers do not, therefore, appear to be the result of differing technological strategies when preparing platforms and removing variably sized flakes from cores. Hence, the employment of differing biomechanical strategies by knappers are likely the result of the adoption of different techniques over the course of an individual's knapping experience.

Although we cannot speak to the exact magnitude of the excess pressures experienced by individual knappers, the distinct knapping strategies seen in Figure 5 and Table 6 clearly demonstrate that biomechanical strategies are available that result in relatively lower loads on the hand during the production of smaller flakes. It is tempting to link the strategies uncovered here with knapping skill. However, as discussed above, such a relationship does not appear warranted. An alternative possibility is that the employment of a relatively inefficient technique that results in relatively greater loads on the hand may be linked to a different biomechanical aspect of knapping (e.g. wrist extension, torso rotation) that was not recorded here. Certainly, we cannot rule out the possibility that the relatively greater pressures experienced by some individuals during the detachment of smaller flakes was due to the influence of a shared biomechanical technique in a differing regard. Future research may be able to shed further light upon this matter.

We also investigated relationships between manual pressure and the Exterior Platform Angle (EPA), Platform Depth, Elongation, and Relative Thinness of flakes (Table 5). EPA and Platform Depth displayed a significant relationship with manual pressure in only three instances across both types of reduction sequence, and the strength of these relationships was low (i.e. $\mathrm{R}^{2}$ values were <.100). Further, examination on an individual knapper basis revealed only one significant relationship is present between either EPA or Platform Depth and manual 
pressure (Supplementary Material 1). When examined at both an individual and combined level, the elongation and relative thinness of flakes did not display significant relationships with manual pressure (Table 5; Supplementary Material 1). The EPA, Platform Depth, Elongation, and Relative Thinness of flakes do not, therefore, appear to be useful morphological attributes of flakes from which to reconstruct the manual pressures experienced by Lower Palaeolithic hominins (irrespective of differing strategies that may have been followed).

With regards to EPA and Platform Depth these results may be considered surprising as the force needed to remove a flake (and therefore the corollary reaction force resisted by the gripping digits) has previously been described as being a function of these two variables (due to their close relationship with a flake's size; Chai and Lawn, 2007; Dibble and Rezek, 2009). As previously noted elsewhere (Cotterell and Kamminga, 1987; Dibble and Whittaker, 1981; Dogandžić et al., 2015; Magnani et al., 2014), however, because of the complex and codependent relationships that exist between a range of independent factors (including EPA and Platform Depth) that influence the final form of flakes, the predictive strength of a given variable can be degraded or lost as a result of other intermediate variables. Certainly, relationships as strong as those identified in the controlled laboratory study by Dibble and Rezek (2009: 1952) between flake weight and indenture force are unlikely to be repeated when examining EPA or platform depth. In other words, it was always likely to be the case that there would be a greater degree of 'noise' when using a flake's platform attributes to reconstruct variables that are consequent to the force of a hammerstone indenture, as opposed to using the flake's size itself. This is particularly likely within a replicative experiment such as that presented here, where the greater external validity provided by actualistic experiments increases the number of variables influencing these relationships (Eren et al., 2016). As a result, the relative lack of significant results identified here for EPA and platform depth are not surprising. Further, although a direct relationship between the striking force of a hammerstone and the pressures required to securely grip it during striking have been predicted here, this relationship has never been directly tested. Indeed, although it is logical that greater hammerstone striking forces would result in increased reaction forces and a greater requirement to secure the hammerstone (which in turn lead to greater pressure records), it is possible that this relationship may not be linear and, in turn, may reduce the strength of any relationships.

As discussed above the size of the hammerstone used to detach a flake is also likely to significantly impact the amount of manual pressure experienced (see also: Supplementary 
Material 3). This introduces a further level of complexity when trying to reconstruct the manual pressures experienced in the dominant hand of Palaeolithic stone tool producers as direct links between specific hammerstones and flakes are rarely (if ever) reliably identified within the artefact record. Similar problems arise when consideration is given to knappers applying additional techniques that may facilitate the propagation of larger flakes (e.g. supporting the dorsal surface of a flake during its detachment [Cotterell and Kamminga, 1990]). In other words, there are a number of additional factors that may influence relationships between flake attributes and manual pressures that are archaeologically invisible. In turn, this would create additional 'noise' surrounding the accurate reconstruction of manual pressure from flake artefacts.

It is an unfortunate consequence of undertaking experiments with expert knappers that the number of individuals investigated is often limited. The extent to which any biomechanical differences between individuals are similarly demonstrated within larger populations are, therefore, not known. Indeed, despite the substantial number of flakes examined here and the robust analyses conducted for this set of knappers, the present results should be viewed with some caution when being applied at a population level. It would be valuable if future experiments were able to examine differences in biomechanical strategies with a larger number of knappers. One potential route for this may be through the examination of a large cohort of novice knappers and the examination of biomechanical differences as their skill/expertise develops.

\section{Conclusion}

It has been demonstrated here that there is considerable variation amongst stone tool producers with regards to how much pressure they experience across the distal phalanges of their dominant hand during the detachment of relatively small flakes. Certainly, the presence of small flakes within Palaeolithic assemblages does not necessarily indicate that low manual pressures were experienced by stone tool producers. Particularly large flakes, however, appear to require the exertion and resistance of relatively high manual pressures. The presence of large stone flakes (i.e. $>10 \mathrm{~cm}$ ) within Lower Palaeolithic assemblages, such as those associated with the Acheulean techno-complex, may then, indicate that relatively great manual pressures were able to be exerted and resisted by the hominin populations responsible for their production. Our finding that there are distinctions in the type of biomechanical strategy employed by 
individuals during stone tool production is, however, perhaps the most intriguing aspect of the present research. It is our hope that future research will be able to build upon the work presented here in order to investigate and explain these phenomena in more detail.

\section{Acknowledgements}

We are grateful to the knappers who took part in the experiment, Tracy Kivell for feedback provided on an earlier draft of this paper, and the anonymous reviewers for their helpful suggestions during the review process. AK's research is funded by a British Academy Postdoctoral Fellowship. CD is funded by European Research Council Starting Grant \#336301. 


\section{References}

Abramoff, M.D., Magalhaes, P.J., Ram, S.J., 2004. Image Processing with ImageJ. Biophotonics International, 11 (7): 36-42

Almécija, S., Alba, D.M., 2014. On manual proportions and pad-to-pad precision grasping in Australopithecus afarensis. Journal of Human Evolution, 73: 88-92

Almécija, S., Smaers, J.B., Jungers, W.L., 2015. The evolution of human and ape proportions. Nature Communications 6: 7717

Ambrose, S.H., 2010. Coevolution of composite-tool technology, constructive memory, and language: Implications for the evolution of modern human behaviour. Current Anthropology, 51 (1): $135-147$

de Beaune, S.A., 2004. The invention of technology. Current Anthropology, 45 (2): 139-162

Beaune, S.A., Coolidge, F.L., Wynn, T., 2009. Cognitive Archaeology and Human Evolution. Cambridge University Press, Cambridge

Bello, S.M., 2011. New results from the examination of cut-marks using three-dimensional imaging. In: Ashton, N., Lewis, S., and Stringer, C., (Eds.) The Ancient Human Occupation of Britain. Elsevier, Amsterdam. pp. 249-262

Bello, S.M., Parfitt, S.A., Stringer, C.B., 2009. Quantitative micromorphological analyses of cut marks produced by ancient and modern handaxes. Journal of Archaeological Science, 36: $1869-1880$

Chai, H., Lawn, B.R., 2007. Edge chipping of brittle materials: effect of side-wall inclination and loading angle. International Journal of Fracture, 145: 159-165

Cotterell, B., Kamminga, J., 1987. The formation of flakes. American Antiquity, 52 (4): 675708

Cotterell, B., Kamminga, J., 1990. Mechanics of Pre-Industrial Technology. Cambridge University Press, Cambridge.

Delagnes, A., Roche, H., 2005. Late Pliocene hominid knapping skills: the case of Lokalalei 2C, West Turkana, Kenya. Journal of Human Evolution, 48 (5): 435-472

Dibble, H.L., Whittaker, J.C., 1981. New experimental evidence on the relation between percussion flaking and flake variation. Journal of Archaeological Science, 8: 283-296

Dibble, H.L. Rezek, Z., 2009. Introducing a new experimental design for controlled studies of flake formation: results for exterior platform angle, platform depth, angle of blow, velocity, and force. Journal of Archaeological Science, 36: 1945-1954

Dogandžić, T., Braun, D.R., McPherron, S.P., 2015. Edge length and surface area of a blank: experimental assessment of measures, size prediction, and utility. PLoS ONE, 10 (9): e0133984 
Eren, M.I., Pattern, R.J., O’Brien, M.J., Meltzer, D.J., 2013. Refuting the technological cornerstone of the Ice-Age Atlantic crossing hypothesis. Journal of Archaeological Science, 40 (7): 2934-2941

Eren, M.I., Lycett, S.J., Patten, R.J., Buchanan, B., Pargeter, J., O’Brien, M.J., 2016. Test, model, and method validation: the role of experimental stone artifact replication in hypothesis-driven archaeology. Ethnoarchaeology 8 (2): 103-136

Faisal, A., Stout, D., Apel, J., Bradley, B., 2010. The manipulative complexity of Lower Paleolithic stone toolmaking. PLoS One, 5 (11): e13718

Gamble, C., Gowlett, J., Dunbar, R., 2014. Thinking Big: How the Evolution of Social Life Shaped the Human Mind. Thames and Hudson, London

Gowlett, J.A.J., 2015. Variability in an early hominin percussive tradition: the Acheulean versus cultural variation in modern chimpanzee artefacts. Phil. Trans. R. Soc. B 370: 20140358

Gowlett, J., Gamble, C., Dunbar, R., 2012. Human evolution and the archaeology of the social brain. Current Anthropology, 53 (6): 693-722

Harmand S, Lewis JE, Feibel CS, Lepre CJ, Prat S, Lenoble A, et al. (2015) 3.3-million-yearold stone tools from Lomekwi 3, West Turkana, Kenya. Nature, 521:310-315

Hamrick, M.W., Churchill, S.E., Schmitt, D., Hylander, W.L., 1998. EMG of the human flexor pollicis longus muscle: implications for the evolution of hominid tool use. Journal of Human Evolution, 34 (2): 123-136

Isaac, G.I., 1969. Studies of early culture in East Africa. World Archaeology, 1 (1); 1-28

Key, A.J.M., 2016. Integrating mechanical and ergonomic research within functional and morphological analyses of lithic cutting technology: key principles and future experimental directions. Ethnoarchaeology, 8 (1): 69-89

Key, A.J.M., Lycett, S.J., 2011. Technology based evolution? A biometric test of the effects of handsize versus tool form on efficiency in an experimental cutting task. Journal of Archaeological Science, 38 (7): 1663-1670.

Key, A.J.M., Lycett, S.J., in press. Investigating interrelationships between Lower Palaeolithic stone tool effectiveness and tool user biometric variation: implications for technological and evolutionary changes. Archaeological and Anthropological Sciences doi: $10.1007 / \mathrm{s} 12520-016-0433-\mathrm{x}$

Key, A.J.M. Dunmore, C.J., 2015. The evolution of the hominin thumb and the influence exerted by the non-dominant hand during stone tool production. Journal of Human Evolution, 78: 60-69

Key, A.J.M., Stemp, W.J., Morozov, M., Proffitt, T., de la Torre, I., 2015. Is loading a significantly influential factor in the development of lithic microwear? an experimental test using LSCM on basalt from Olduvai Gorge. Journal of Archaeological Method and Theory, 22 (4): 1193: 1214 
Kivell, T.L., 2015. Evidence in hand: recent discoveries and the early evolution of human manual manipulation. Phil. Trans. R. Soc. B., 370 (1682): 20150105

Krantz, G.S., 1960. Evolution of the human hand and the great hand-axe tradition. Kroeber Anthropology Society, 23: 114-128

Lycett, S.J., Gowlett, J.A.J., 2008. On questions surrounding the Acheulean 'tradition'. World Archaeology, 40 (3): 295-315

Lycett, S.J., von Cramon-Taubadel, N., 2015. Toward a "quantitative genetic" approach to lithic variation. Journal of Archaeological Method and Theory, 22 (2): 646-675

Magnani, M., Rezek, Z., Lin, S.C., Chan, A., Dibble, H.L., 2014. Flake variation in relation to the application of force. Journal of Archaeological Science, 46: 37-49

Maki, J.M., 2013. The Biomechanics of Spear Throwing: An Analysis of the Effects of Anatomical Variation on Throwing Performance, with Implications for the Fossil Record. Unpublished PhD Thesis, Washington University in St Louis.

Marzke, M.W., 1997. Precision grips, hand morphology, and tools. American Journal of Physical Anthropology, 102 (1): 91-110

Marzke, M.W., 2013. Tool making, hand morphology and fossil hominins. Phil. Trans. R. Soc. B., 368 (1630): 20120414

Marzke, M.W. Shackley, M.S., 1986. Hominid hand use on the Pliocene and Pleistocene: evidence from experimental archaeology and comparative morphology. Journal of Human Evolution, 15 (6): 439-460

Marzke M.W., Toth, N., Schick, K., Reece, S., Steinberg, B., Hunt, K., Linscheid, R.L., An, K.-N., 1998. EMG study of hand muscle recruitment during hard hammer percussion manufacture of Oldowan tools. American Journal of Physical Anthropology, 105: 315-332

Morgan, T.J.H., Uomini, N.T., Rendell, L.E., Chouinard-Thuly, L., Street, S.E., Lewis, H.M., Corss, C.P., Evans, C., Kearney, R., de la Torre, I., Whiten, A., Laland, K.N., 2015.

Experimental evidence for the co-evolution of hominin tool-making and language. Nature Communications, 6: 6029

Napier, J. 1962. Fossil hand bones from Olduvai Gorge. Nature 196: 409-411

Newcomer, M.H., 1971. Some quantitative experiments in handaxe manufacture. World Archaeology, 3 (1): 85-94

Nonaka, T., Bril, B., Rein, R., 2010. How do stone knappers predict and control the outcome of flaking? Implications for understanding early stone tool technology. Journal of Human Evolution, 59: 155-167

Pfleging, J., Stücheli, M., Iovita, R., Buchli, J., 2015. Dynamic monitoring reveals motor task characteristics in prehistoric technical gestures. PLoS ONE 10 (8): e0134579

Rolian, C., Lieberman, D.E., Zermeno, J.P., 2011. Hand biomechanics during simulated stone tool use. Journal of Human Evolution, 61 (1): 26-41 
Roux, V., Bril, G., Dietrich, G., 1995. Skills and learning difficulties involved in stone knapping: The case of stone-bead knapping in Khambhat, India. World Archaeology, 27 (1): 63-87

Roux, V., David, E., 2005. Planning abilities as a dynamic Perceptual-motor skill: an actualistic study of different levels of expertise involved in stone knapping. In: Roux, V. and Bril, B. (Eds.) Stone Knapping: the Necessary Conditions for a Uniquely Hominin Behaviour. Oxbow Books, Oxford. pp. 91-108

Schillinger, K., Mesoudi, A., and Lycett, S.J., 2015. The impact of imitative versus emulative learning mechanisms on artifactual variation: implications for the evolution of material culture. Evolution and Human Behavior, 36 (6): 446-455

Semaw, S., Rogers, Stout, D., 2009. The Oldowan-Acheulean transition: is there a "Developed Oldowan" artifact tradition? In: Camps, M., and Chauhan, P. (Eds.) Sourcebook of Paleolithic Transitions. Springer, New York. pp. 173-193

Sharon, G., 2009. Acheulian giant-core technology. Current Anthropology, 50 (3): 335-367

Shaw, C.N., Hofmann, C.L., Petraglia, M.D., Stock, J.T., Gottschall, J.S., 2012. Neanderthal humeri may reflect adaptation to scraping tasks, but not spear thrusting. PLoS ONE, 7 (7): e40349

Skinner, M.M., Stephens, N.B., Tsegai, Z.J., Foote, A.C., Nguyen, N.H., Gorss, T., Pahr, D.H., Hublin, J.-J., Kivell, T.L., 2015. Human-like hand use in Australopithecus africanus. Science, 347 (6220): 395-399

Stemp, W.J., Morozov, M., Key, A.J.M., 2015. Quantifying lithic microwear with load variation on experimental basalt flakes using LSCM and area-scale fractal complexity (Asfc). Surface Topography: Metrology and Properties 3 (3): e034006

Stephens, N.B., Kivell, T.L., Gross, T., Pahr, D.H., Lazenby, R.A., Hublin, J.-J., Hershkovitz, I., Skinner, M.M., 2016. Trabecular architecture in the thumb of Pan and Homo: implications for investigating hand use, loading, and hand preference in the fossil record. American Journal of Physical Anthropology, doi: 10.1002/ajpa.23061

Stout, D., 2002. Skill and cognition in stone tool production: An ethnographic case study from Irian Jaya. Current Anthropology, 43 (5): 693-722

Stout, D., 2011. Stone toolmaking and the evolution of human culture and cognition. Phil. Trans. R. Soc. B, 366: 1050-1059

Stout, D., Toth, N., Schick, K., Chaminade, T., 2008. Neural correlates of Early Stone Age toolmaking: technology, language and cognition in human evolution. Phil. Trans. R. Soc. B, 363 (1499): 1939-1949

Stout, D., Semaw, S., Rogers, M.J., Cauche, D., 2010. Technological variation in the earliest Oldowan from Gona, Afar, Ethiopia. Journal of Human Evolution, 58 (6): 474-491

Tocheri, M.W., Orr, C.M., Jacofsky, M.C., Marzke, M.W., 2008. The evolutionary history of the hominin hand since the last common ancestor of Pan and Homo. Journal of Anatomy, 212 (4): $544-562$ 
Toth, N., 1985. The Oldowan reassessed: A close look at early stone artefacts. Journal of Archaeological Science, 12 (2): 101-120

Uomini, N.T. Meyer, G.F., 2013. Shared brain lateralization patterns in language and Acheulean stone tool production: A functional transcranial doppler ultrasound study. PLoS One, 8 (8): e72693

Washburn, S. L., 1959. Speculations on the interrelations of the history of tools and biological evolution. Human Biology, 31(1): 21-31.

Weedman Arthur, K., 2010. Feminine knowledge and skill reconsidered: Women and flaked stone tools. American Anthropologist, 112 (2): 228-243

Williams, E.-M., Gordon, A.D., Richmond, B.G., 2010. Upper limb kinematics and the role of the wrist during stone tool production. American Journal of Physical Anthropology, 143 (1): $143-145$

Williams, E.-M., Gordon, A.D., Richmond, B.G., 2012. Hand pressure distribution during Oldowan stone tool production. Journal of Human Evolution, 62 (4): 520-532

Williams, E.-M., Gordon, A.D., Richmond, B.G., 2014. Biomechanical strategies for accuracy and force generation during stone tool production. Journal of Human Evolution, 72: $52-63$

Williams-Hatala, E.-M., Key, A.J.M., Stephens, N.B., Kivell, T.L., 2016. Predictions for an osteological signature of stone tool behaviors in hard tissue anatomy. American Journal of Physical Anthropology, 159 (s62): 335-335

Winton, V. (2005) An investigation of knapping-skill development in the manufacture of Palaeolithic handaxes. In: Roux, V. and Bril, B. (Eds.) Stone Knapping: the Necessary Conditions for a Uniquely Hominin Behaviour. Oxbow Books, Oxford. pp. 109-118 Wynn, T., 2002. Archaeology and cognitive evolution. Behavioural and Brain Sciences, 25: $389-438$

Zupancich, A., Lemorini, C., Gopher, A., Barkai, R., 2015. On Quina and demi-Quina scraper handling: Preliminary results from the late Lower Paleolithic site of Qesem Cave, Israel. Quaternary International, 398: 94-102 


\section{Figures}

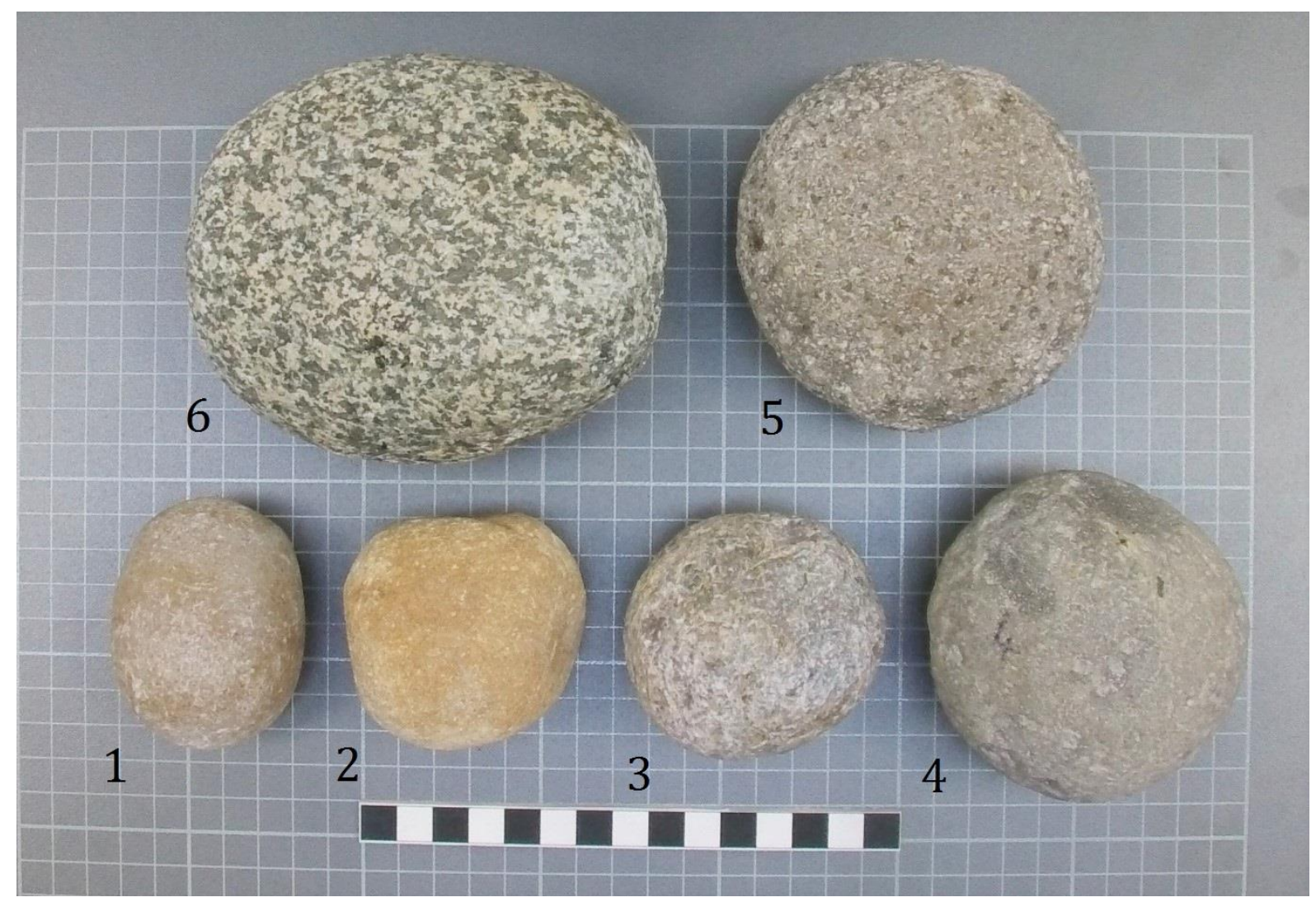

Figure 1: The six hammerstones that were presented to each knapper (scale bar $=15 \mathrm{~cm}$ ). Hammerstones 1 through 6 are arranged in an anti-clockwise order from the bottom-left. 

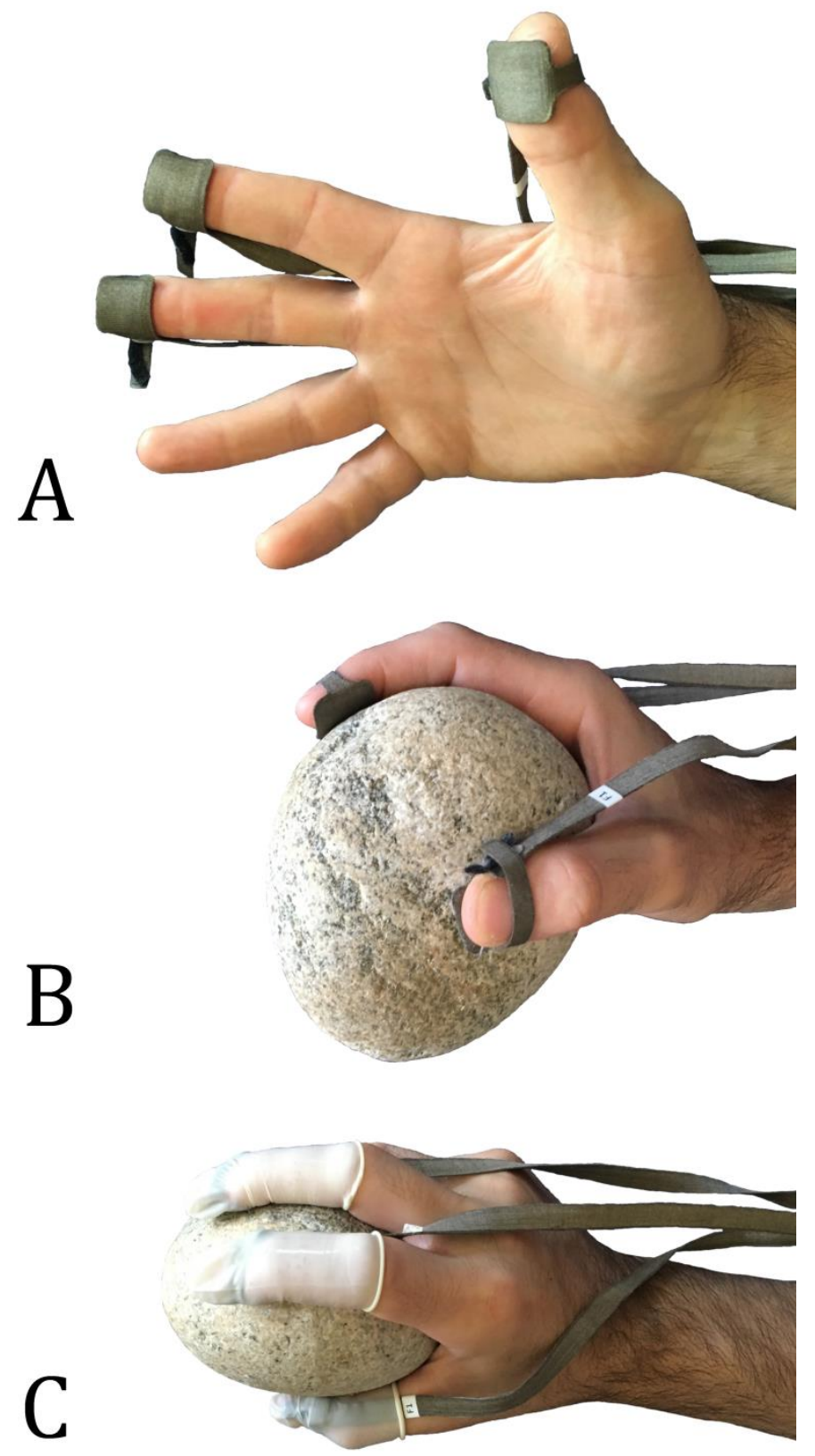

Figure 2: The Novel Pliance ${ }^{\circledR}$ system and where sensors were attached on the hand of participants. The three methods used to secure the sensors in place are also depicted (finger cots, double sided tape, and Velcro strap). 


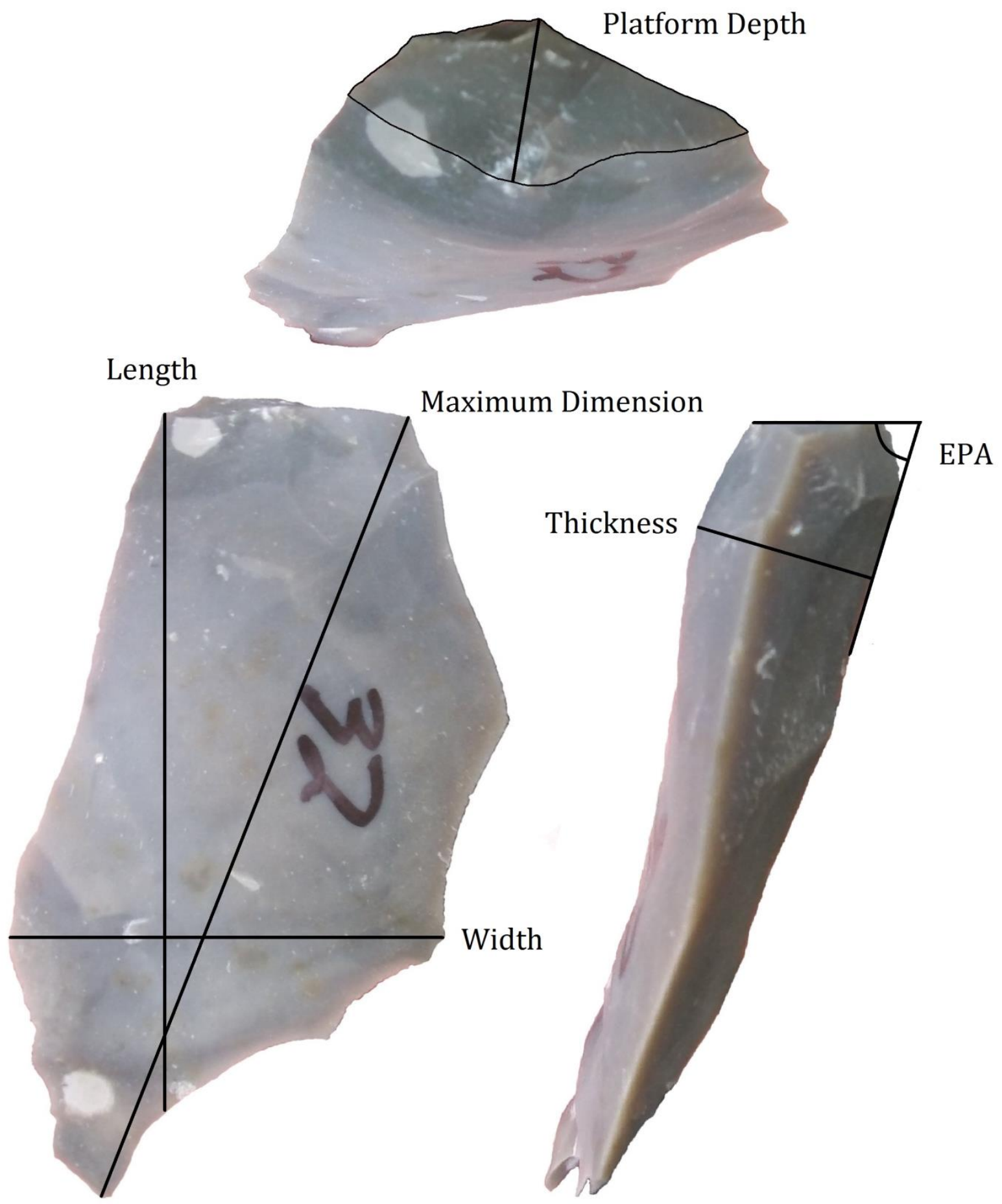

Figure 3. Depiction of the morphological variables recorded from each of the 567 flakes detached during this experiment. 

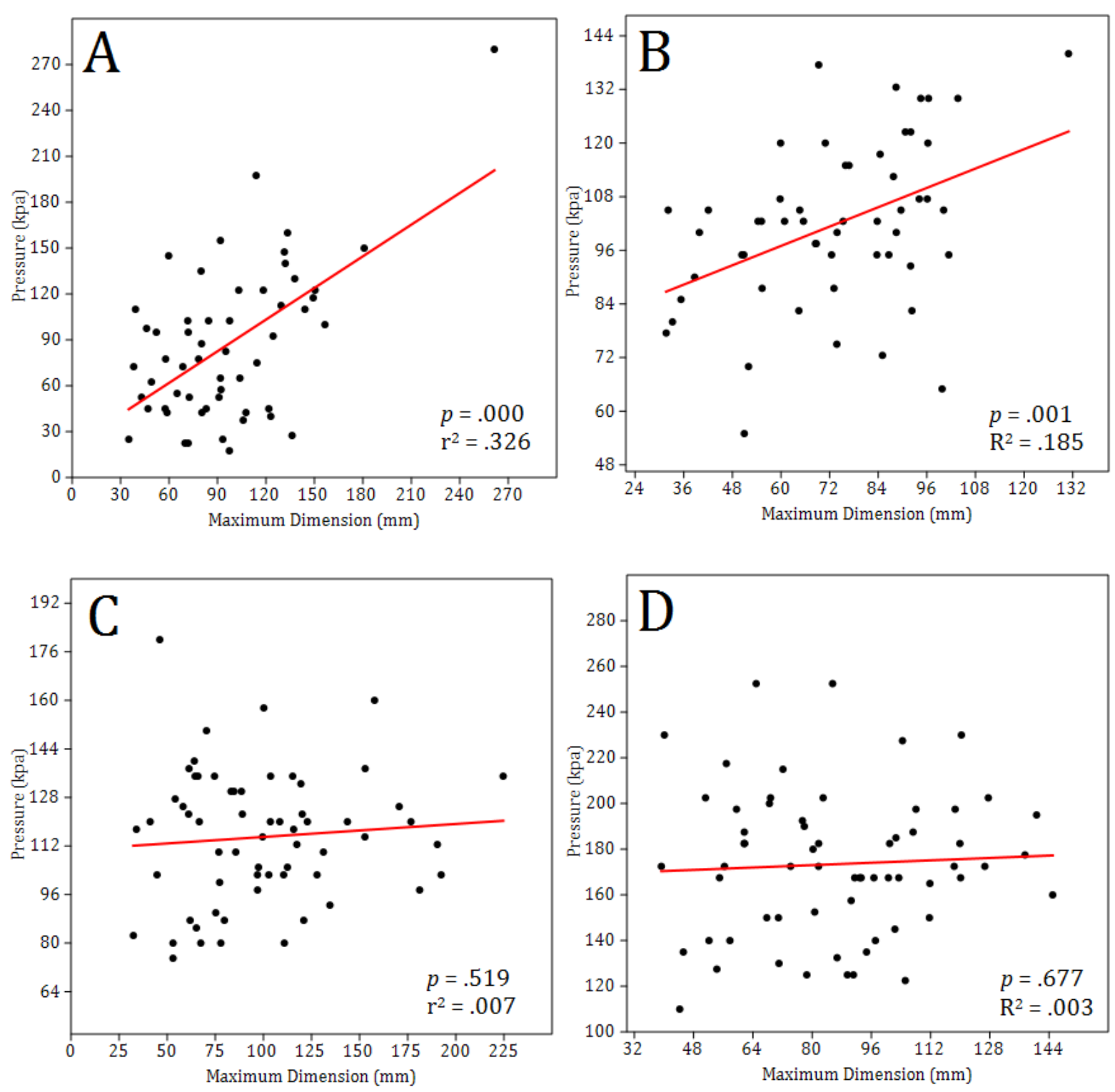

Figure 4: Regressions between the maximum dimension of flakes from the combined sample of Oldowan and Acheulean reductions and the pressures experienced through the thumb of participants nine (a), two (b), four (c), and five (d). Note that even with the removal of the outlier in image 6 a there is a significant relationship $\left(P=.008, \mathrm{R}^{2}=.182\right)$. 

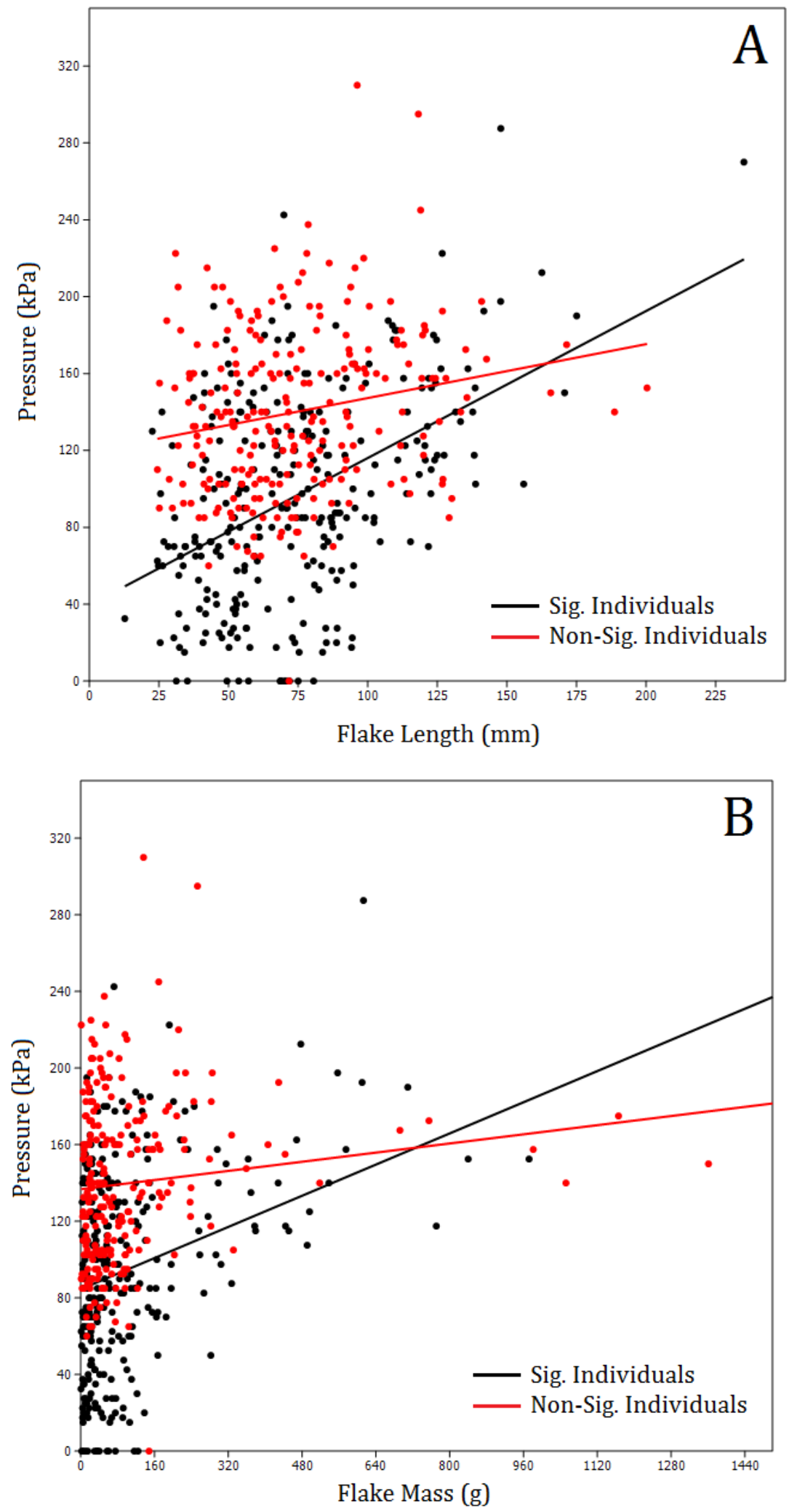

Figure 5: Plots between flake length (A) and mass (B) and peak pressure in the distal phalanx of the index finger during flake removals. In both instances, the five individuals that did display significant regressions between pressure and flake size/mass are in black, while the four individuals that did not display significant regressions are in red. 

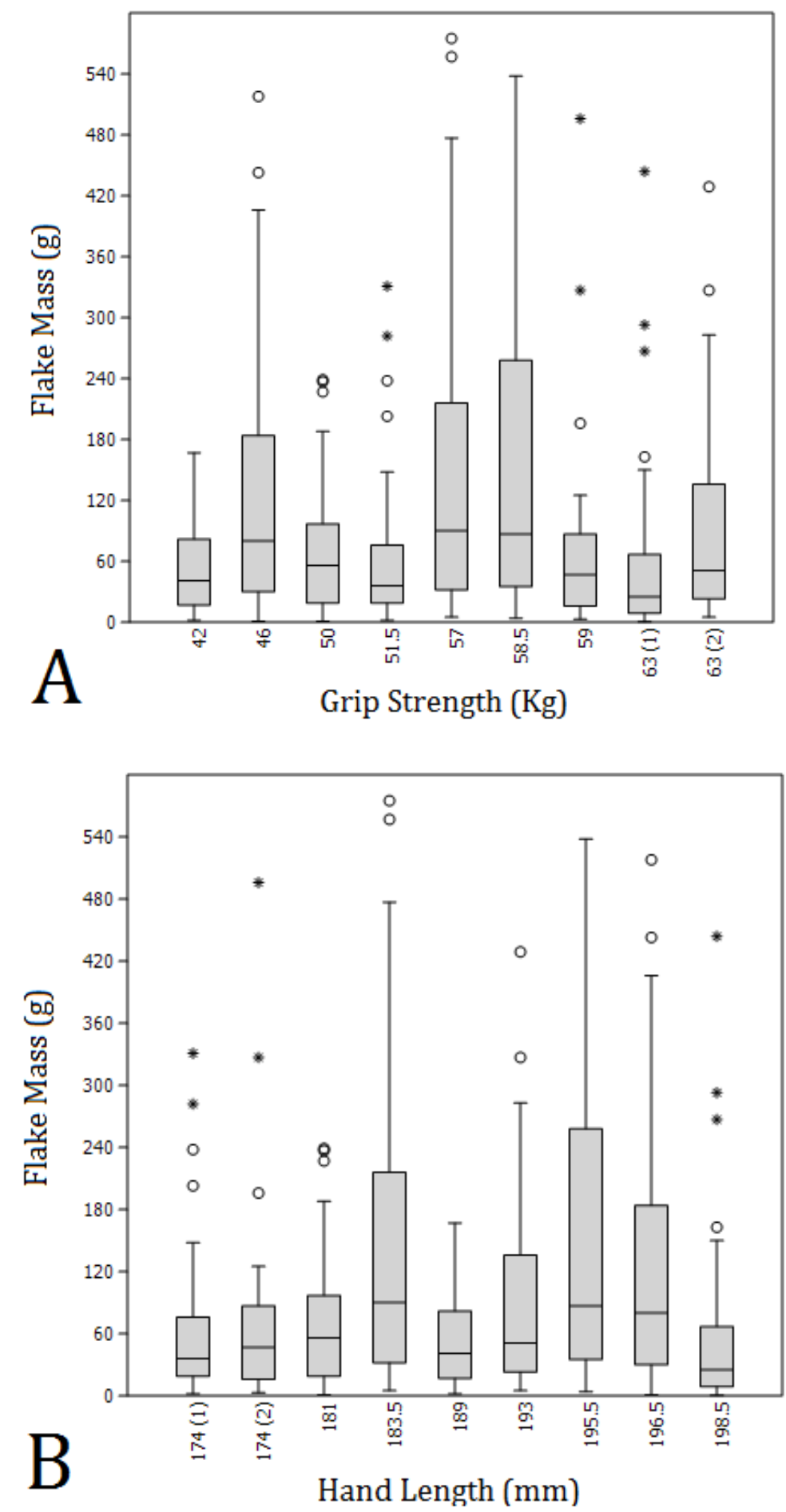

Figure 6: Box plots illustrating knapper grip strength (A) and hand length (B) against the Mass of the flakes detached during both this Oldowan and Acheulean flake reducing sequences. 


\section{Tables}

Table 1: Descriptive data for each of the knappers included in these analyses.

\begin{tabular}{|c|c|c|c|c|c|c|}
\hline $\begin{array}{c}\text { Participant } \\
\#\end{array}$ & $\begin{array}{c}\text { Hand } \\
\text { Length } \\
(\mathbf{m m})\end{array}$ & $\begin{array}{c}\text { Grip } \\
\text { Strength } \\
(\mathbf{k g})\end{array}$ & $\begin{array}{c}\text { Pad-to-Side } \\
\text { Pinch Strength } \\
(\mathbf{k g})\end{array}$ & $\begin{array}{c}\text { Years of } \\
\text { Knapping } \\
\text { Experience }\end{array}$ & $\begin{array}{c}\text { Oldowan } \\
\text { Flaking } \\
\text { Success } \\
(\%)\end{array}$ & $\begin{array}{c}\text { Acheulean } \\
\text { Flaking Success } \\
(\%)\end{array}$ \\
\hline $\mathbf{1}$ & 198.5 & 63 & 12.9 & 5 & 73 & 59 \\
\hline $\mathbf{2}$ & 189 & 42 & 10.2 & 32 & 83 & 83 \\
\hline $\mathbf{3}$ & 183.5 & 57 & 9.7 & 12 & 80 & 77 \\
\hline $\mathbf{4}$ & 196.5 & 46 & 10.4 & 41 & 80 & 62 \\
\hline $\mathbf{5}$ & 193 & 63 & 10.1 & 25 & 53 & 59 \\
\hline $\mathbf{6}$ & 181 & 50 & 10.2 & 14 & 60 & 77 \\
\hline $\mathbf{7}$ & 174 & 59 & 11.3 & 39 & 81 & 70 \\
\hline $\mathbf{8}$ & 174 & 51.5 & 10 & 6.5 & 70 & 89 \\
\hline $\mathbf{9}$ & 195.5 & 58.5 & 10 & 34 & & 50 \\
\hline
\end{tabular}


Table 2: Descriptive data for each of the hammerstones used by participants during both the Oldowan and Acheulean reduction sequences.

\begin{tabular}{|c|c|c|c|c|}
\hline Hammerstone & Length $(\mathrm{mm})$ & Width $(\mathrm{mm})$ & Depth $(\mathrm{mm})$ & Weight $(\mathrm{g})$ \\
\hline 1 & 68 & 50 & 47 & 242 \\
\hline 2 & 68 & 65 & 47 & 289 \\
\hline 3 & 69 & 64 & 60 & 342 \\
\hline 4 & 85 & 82 & 66 & 669 \\
\hline 5 & 98 & 97 & 58 & 835 \\
\hline 6 & 124 & 107 & 83 & 1547 \\
\hline
\end{tabular}


Table 3: Descriptive data for the nine variables recorded from the 276 Oldowan and 291 Acheulean flakes removed during this experiment.

\begin{tabular}{|c|c|c|c|c|}
\hline \multirow{2}{*}{} & \multicolumn{2}{|c|}{$\begin{array}{c}\text { Oldowan } \\
(\mathrm{n}=276)\end{array}$} & \multicolumn{2}{c|}{$\begin{array}{c}\text { Acheulean } \\
(\mathrm{n}=291)\end{array}$} \\
\cline { 2 - 5 } & Mean & S.D. & Mean & S.D. \\
\hline Mass (g) & 124.8 & 217.5 & 99.2 & 198.8 \\
\hline Maximum Dimension (mm) & 87.0 & 33.9 & 82.4 & 34.0 \\
\hline Length (mm) & 79.0 & 31.5 & 69.4 & 30.9 \\
\hline Width (mm) & 62.0 & 26.7 & 61.8 & 27.9 \\
\hline Thickness (mm) & 20.4 & 11.3 & 17.6 & 11.1 \\
\hline Platform Depth (mm) & 14.1 & 8.4 & 12.4 & 8.8 \\
\hline EPA ${ }^{\circ}$ ) & 72.6 & 10.1 & 72.1 & 12.1 \\
\hline Elongation & 1.35 & 3.47 & 1.21 & 0.47 \\
\hline Relative Thinness & 3.47 & 1.34 & 4.02 & 1.57 \\
\hline
\end{tabular}


Table 4: Descriptive data for the nine flake variables recorded during this experiment dependent upon the participant.

\begin{tabular}{|c|c|c|c|c|c|c|c|c|c|c|c|c|c|c|c|c|c|c|}
\hline & \multicolumn{2}{|c|}{1} & \multicolumn{2}{|c|}{2} & \multicolumn{2}{|c|}{3} & \multicolumn{2}{|c|}{4} & \multicolumn{2}{|c|}{5} & \multicolumn{2}{|c|}{6} & \multicolumn{2}{|c|}{7} & \multicolumn{2}{|c|}{8} & \multicolumn{2}{|c|}{9} \\
\hline & Mean & S.D. & Mean & S.D. & Mean & S.D. & Mean & S.D. & Mean & S.D. & Mean & S.D. & Mean & S.D. & Mean & S.D. & Mean & S.D. \\
\hline Mass (g) & 54.5 & 76.6 & 54.9 & 43.9 & 173.7 & 216.1 & 208.8 & 355.1 & 98.9 & 123.5 & 67.7 & 60.7 & 69.4 & 91 & 59.6 & 67.9 & 195.3 & 373.7 \\
\hline $\begin{array}{l}\text { Maximum Dimension } \\
\qquad(\mathrm{mm})\end{array}$ & 69 & 28.3 & 73.2 & 21.9 & 99.2 & 39.5 & 99.5 & 42.4 & 86.3 & 26.1 & 77.4 & 27.3 & 81.9 & 25.2 & 76.3 & 28.2 & 96.1 & 41.4 \\
\hline Length (mm) & 59.5 & 26.2 & 62.4 & 18.9 & 87.9 & 34.4 & 88.9 & 38.4 & 74.1 & 26.3 & 67.2 & 23.7 & 73.9 & 25.4 & 66.2 & 26.2 & 84.5 & 40.1 \\
\hline Width (mm) & 51 & 21 & 54.6 & 23.1 & 72 & 31.3 & 69 & 33.5 & 64.2 & 26.9 & 61.3 & 23.2 & 53.8 & 20.6 & 57.1 & 18 & 70.8 & 32.9 \\
\hline Thickness (mm) & 14.9 & 9.3 & 17 & 8.7 & 21.4 & 10.9 & 23.3 & 15.6 & 20.5 & 10.3 & 17.1 & 7.9 & 17.7 & 12.9 & 14.5 & 7.5 & 23.9 & 12.4 \\
\hline Platform Depth (mm) & 9.2 & 5.3 & 11.6 & 7.9 & 13 & 6.9 & 17 & 12.6 & 15.7 & 9.5 & 12.1 & 6.2 & 12.5 & 7.6 & 9.6 & 5 & 18.1 & 9.5 \\
\hline $\operatorname{EPA}\left(^{\circ}\right)$ & 75.9 & 10 & 67 & 9.8 & 72.4 & 10.5 & 70.1 & 10.5 & 73.7 & 10.2 & 71.7 & 10.6 & 76.2 & 8.2 & 77 & 13.1 & 66.7 & 12.1 \\
\hline Elongation & 1.22 & 0.37 & 1.29 & 0.53 & 1.30 & 0.42 & 1.37 & 0.44 & 1.27 & 0.54 & 1.19 & 0.49 & 1.46 & 0.52 & 1.19 & 0.38 & 1.27 & 0.47 \\
\hline Relative Thinness & 3.97 & 1.56 & 3.65 & 1.67 & 3.73 & 1.38 & 3.45 & 1.32 & 3.41 & 1.14 & 3.90 & 1.12 & 3.86 & 1.79 & 4.63 & 1.80 & 3.21 & 1.13 \\
\hline
\end{tabular}


Table 5: Regression of flake mass, size, platform depth, EPA, elongation, and relative thinness against the pressures experienced by the distal phalanx of digits 1-3 on the dominant hand during Oldowan and Acheulean stone tool production. Flake size was investigated via multiple regression while the other five variables were examined using standard regression. Bold indicates significant values subsequent the Bonferroni correction $(\alpha=.008)$.

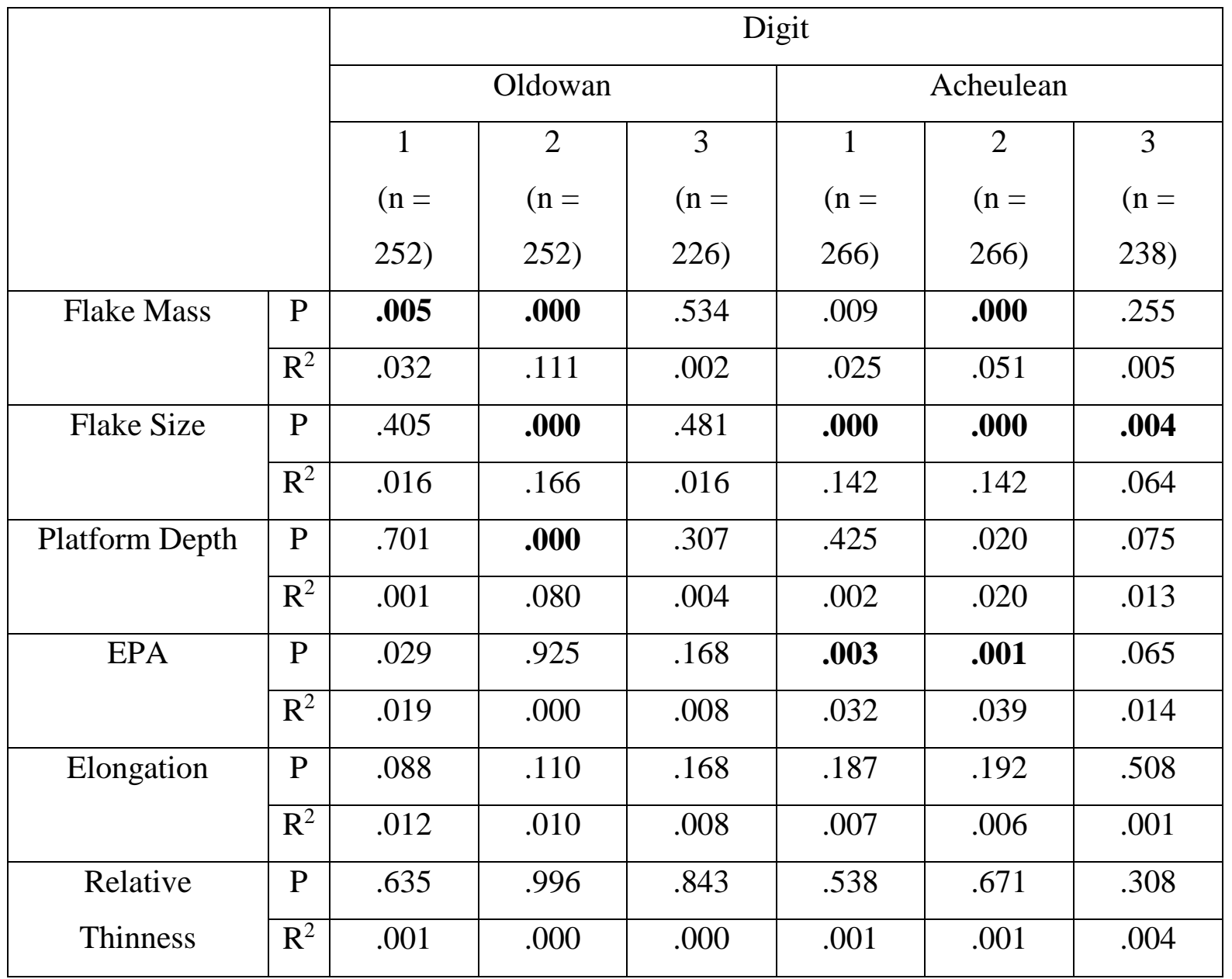


Table 6: Regression of flake mass and size against the maximum pressures experienced by the distal phalanx of digits 1-3 on the dominant hand during Lower Palaeolithic (i.e. Oldowan and Acheulean data were combined) flake production sequences. Flake size was investigated via multiple regression while mass was a standard regression. Bold indicates significant values subsequent the Bonferroni correction $(\alpha=.002)$.

\begin{tabular}{|c|c|c|c|c|c|c|c|}
\hline \multicolumn{2}{|c|}{ Participant } & \multicolumn{6}{|c|}{ Digit } \\
\hline & & \multicolumn{3}{|c|}{ Mass } & \multicolumn{3}{|c|}{ Flake Size } \\
\hline & & 1 & 2 & 3 & 1 & 2 & 3 \\
\hline \multirow[t]{2}{*}{1} & $\mathrm{P}$ & .001 & .001 & .086 & .000 & .027. & .012 \\
\hline & $\mathrm{R}^{2}$ & .159 & .153 & .047 & .296 & .167 & .194 \\
\hline \multirow[t]{2}{*}{2} & $\mathrm{P}$ & .003 & .025 & - & .010 & .002 & - \\
\hline & $\mathrm{R}^{2}$ & .161 & .093 & - & .233 & .291 & - \\
\hline \multirow[t]{2}{*}{3} & $\mathrm{P}$ & .006 & .012 & .000 & .018 & .008 & .000 \\
\hline & $\mathrm{R}^{2}$ & .113 & .094 & .246 & .175 & .200 & .300 \\
\hline \multirow[t]{2}{*}{4} & $\mathrm{P}$ & .238 & .929 & .162 & .586 & .841 & .010 \\
\hline & $\mathrm{R}^{2}$ & .023 & .000 & .032 & .048 & .024 & .204 \\
\hline \multirow[t]{2}{*}{5} & $\mathrm{P}$ & .870 & .217 & .251 & .787 & .054 & .040 \\
\hline & $\mathrm{R}^{2}$ & .000 & .025 & .022 & .029 & .146 & .156 \\
\hline \multirow[t]{2}{*}{6} & $\mathrm{P}$ & .065 & .380 & .295 & .037 & .686 & .413 \\
\hline & $\mathrm{R}^{2}$ & .063 & .015 & .021 & .182 & .044 & .074 \\
\hline \multirow[t]{2}{*}{7} & $\mathrm{P}$ & .000 & .463 & .000 & .017 & .043 & .005 \\
\hline & $\mathrm{R}^{2}$ & .297 & .014 & .401 & .279 & .234 & .331 \\
\hline \multirow[t]{2}{*}{8} & $\mathrm{P}$ & .164 & .882 & .010 & .054 & .359 & .076 \\
\hline & $\mathrm{R}^{2}$ & .034 & .000 & .112 & .158 & .078 & .145 \\
\hline \multirow[t]{2}{*}{9} & $\mathrm{P}$ & .000 & .000 & .140 & .000 & .000 & .002 \\
\hline & $\mathrm{R}^{2}$ & .370 & .317 & .041 & .354 & .384 & .284 \\
\hline
\end{tabular}


Table 7: ANCOVA analyses examining strength of relationship differences between the two groups of knappers identified in the knapper dependent linear regressions. Analyses were undertaken for both flake size (in this case length) and mass (g) and all three digits.

\begin{tabular}{|c|c|c|c|c|c|c|c|c|c|c|c|c|}
\hline & \multicolumn{6}{|c|}{ Flake Mass } & \multicolumn{6}{|c|}{ Flake Length } \\
\hline \multirow[t]{2}{*}{ Digit } & \multicolumn{2}{|c|}{$\mathbf{1}$} & \multicolumn{2}{|c|}{2} & \multicolumn{2}{|c|}{3} & \multicolumn{2}{|c|}{1} & \multicolumn{2}{|c|}{2} & \multicolumn{2}{|c|}{3} \\
\hline & Sig. & $\begin{array}{c}\text { Non- } \\
\text { Sig. }\end{array}$ & Sig. & $\begin{array}{c}\text { Non- } \\
\text { Sig. }\end{array}$ & Sig. & $\begin{array}{l}\text { Non- } \\
\text { Sig. }\end{array}$ & Sig. & $\begin{array}{c}\text { Non- } \\
\text { Sig. }\end{array}$ & Sig. & $\begin{array}{l}\text { Non- } \\
\text { Sig. }\end{array}$ & Sig. & $\begin{array}{l}\text { Non- } \\
\text { Sig. }\end{array}$ \\
\hline Slope & .070 & .006 & .102 & .029 & .042 & -.009 & .530 & .199 & .765 & .280 & .346 & .007 \\
\hline$P$ & \multicolumn{2}{|c|}{.004} & \multicolumn{2}{|c|}{.000} & \multicolumn{2}{|c|}{.007} & \multicolumn{2}{|c|}{.022} & \multicolumn{2}{|c|}{.000} & \multicolumn{2}{|c|}{.006} \\
\hline
\end{tabular}

